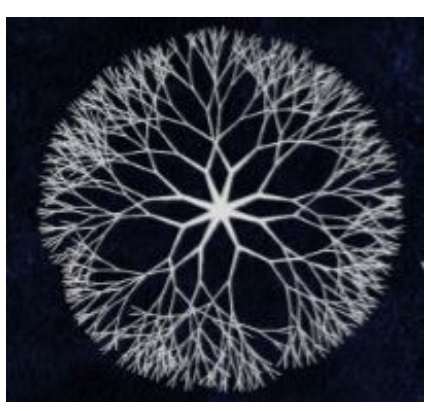

\title{
A disciplina Gravitação no Curso de Licenciatura em Física da USP: objetivos e fundamentos de uma proposta guiada pela história e filosofia da ciência
}

\author{
Flávia Polati \\ Doutoranda IF-USP \\ flaviapolati@gmail.com
}

\author{
Valéria Silva Dias \\ Doutora em Educação para a Ciência \\ Professora IF-USP \\ vsdias@if.usp.br
}

\author{
João Zanetic \\ Doutor em Ensino de Física \\ IF-USP \\ zanetic@if.usp.br
}

Recebido em 02/07/2017. Aprovado em 10/08/2017.

Como citar este artigo: Polati, F.; Dias, V. S.; Zanetic, J. “A disciplina Gravitação no Curso de Licenciatura em Física da USP: objetivos e fundamentos de uma proposta guiada pela história e filosofia da ciência”. Khronos, Revista de História da Ciência, $\mathrm{n}^{\circ} 4$, pp. 72 - 83. 2017. Disponível em < http://revistas.usp.br/khronos>. Acesso em dd/mm/aaaa.

Resumo: Atualmente podemos dizer que há um reconhecimento da importância da presença de elementos da história e da filosofia da ciência na sala de aula por inúmeras pesquisas, currículos, diretrizes nacionais e internacionais para o ensino de ciências mundial. Entretanto, uma das dificuldades em levar tais elementos para a sala de aula, recai na formação específica do professor para lidar com os conteúdos científicos e também aspectos da história e da filosofia da ciência inerente aos episódios abordados. Dessa forma, apresentamos neste artigo os fundamentos, objetivos e pressupostos da disciplina Gravitação, regularmente oferecida no $2^{\circ}$ semestre da Licenciatura em Física da USP. Tal disciplina busca introduzir conceitos de Física através do desenvolvimento histórico e filosófico das teorias da Gravitação, partindo desde os gregos até as teorias gravitacionais do século XX. Ao apresentar alguns resultados gerais de três momentos da implementação dessa proposta, buscamos analisar alguns caminhos percorridos pelos docentes que a implementaram, olhando como esta disciplina manteve sua proposta original e quais seus papeis no início da formação de professores e Física.

Palavras-chave: História da Ciência, Filosofia da Ciência CTS, Educação Científica, Ensino de Física. 
The discipline Gravitation in the Course of Degree in Physics of USP: objectives and foundations of a proposal guided by the history and philosophy of science

\begin{abstract}
We can say that there is a recognition of the importance of the presence of elements of the history and philosophy of science in the classroom by countless researches, curricula, national and international guidelines for teaching science in the world. However, one of the difficulties in bringing such elements into the classroom is the specific training of the teacher to deal with the scientific contents and also aspects of the history and philosophy of science inherent to the episodes addressed. Thus, we present in this article the fundamentals, objectives and assumptions of the discipline Gravitation, regularly offered in the 2nd semester of the Degree in Physics of USP. This discipline seeks to introduce concepts of Physics through the historical and philosophical development of theories of Gravitation, starting from the Greeks to the gravitational theories of the twentieth century. In presenting some general results of three moments of the implementation of this proposal, we sought to analyze some of the paths taken by the teachers who implemented it, looking at how this discipline maintained its original proposal and what its roles at the beginning of teacher training and Physics.
\end{abstract}

Keywords: History of Science, Philosophy of Science, Scientific Education, Physics Teaching.

\title{
I. Introdução
}

Desde a década de 1960 a história e a filosofia da ciência vêm sendo introduzidas em orientações curriculares, projetos de ensino e materiais didáticos para a educação em ciências em diversos países. Como exemplos, citamos o Harvard Project Physics (que posteriormente se tornou Project Physics Course) lançado nos Estados Unidos em 1964, o Projeto 2061 lançado em 1985 e publicado em 1989 pela Associação Americana para o Progresso da Ciência (AAAS, 1989) ${ }^{1}$, o novo Currículo Nacional Britânico de Ciências lançado pelo Conselho de Currículo Nacional Britânico em 1988 (NCC, 1988)2 e os Parâmetros Curriculares Nacionais para o Ensino Médio (PCNEM e PCNEM+) lançados no Brasil em 2000 e complementados em 2007 (BRASIL, 2002) 3.

Esses materiais, ainda que diferentes em diversos aspectos, apresentam exemplos de experimentos, proposições teóricas e problemas históricos que estiveram presentes no desenvolvimento do conhecimento científico. Eles sinalizam, ainda hoje, a aposta num ensino que proporcione uma visão de ciência mais atrativa aos estudantes e aos professores, de maneira que seja reconhecida como uma produção humana, vinculada aos interesses pessoais, culturais e políticos dos agentes envolvidos no seu processo de desenvolvimento.

${ }^{1}$ AAAS. American Association for the Advancement of Science. Science for All Americans. AAAS, Washington, 1989.

2 NCC: National Curriculum Council. Science in the National Curriculum, NCC, York, 1988.

${ }^{3}$ BRASIL. Secretaria de Educação Média e Tecnológica. PCNs+ Ensino Médio: orientações educacionais complementares aos Parâmetros Curriculares Nacionais. Ciências da Natureza, Matemática e suas Tecnologias. Brasília: MEC, SEMTEC 2002. 
Além do reconhecimento da ciência como construção humana, acredita-se que os elementos de história e de filosofia nas aulas de ciências podem também auxiliar os estudantes a compreenderem melhor as idealizações, as modelagens e as terminologias que utiliza-se nas ciências.

Esse é um ponto convergente na volumosa literatura sobre a capacidade de ler e compreender ciência: ter essa capacidade é compreender em profundidade as palavras e os conceitos do discurso, então a história e a filosofia da ciência contribuem claramente para desenvolver uma capacidade mais profunda e crítica ${ }^{4}$.

Neste sentido, a tese de Zanetic ${ }^{5}$, Física também é cultura, aponta importantes relações entre a Física e outros ramos do conhecimento humanístico e cultural, como as artes, a história e a filosofia. Ao apresentar sua defesa acerca da necessidade destes elementos estarem presentes nas disciplinas de cursos de licenciatura em Física, Zanetic argumentou que se a Física for ensinada envolvendo elementos da história e filosofia da ciência, pode promover uma formação cognitiva e intelectual que vai além da formação técnica ou "formulista".

A despeito da tese de Zanetic ter se tornado bastante conhecida e ter se transformado em um marco na área de pesquisa em Ensino de Ciências no Brasil, as grades curriculares dos cursos de licenciatura em Física oferecidos no país comportam poucas disciplinas que propõem elementos de história e filosofia da ciência. Normalmente, apenas as disciplinas "Evolução dos Conceitos da Física" ou "História da Física" são oferecidas e de forma "optativa" ou "eletiva" ".

Verificando a presença de disciplinas de história e de filosofia da ciência oferecidas dentre o rol de disciplinas obrigatórias, Moura encontrou exemplos em cursos de licenciaturas oferecidas pela Universidade Federal do Rio de Janeiro (UFRJ), e pela Universidade Federal de Santa Catarina (UFSC). A oferta, no entanto, ocorre apenas no final dos cursos, o que faz com que muitos dos estudantes se deparem com conteúdos epistemológicos apenas ao final de sua formação científica, de maneira desconectada das disciplinas de conteúdos físicos e dos saberes pedagógicos, não permitindo o desenvolvimento de uma visão integrada dos conhecimentos físicos e epistemológicos.

Nos cursos de licenciatura, que formam especialistas por área de conhecimento ou disciplina, é frequente colocar-se o foco quase que exclusivamente nos conteúdos específicos das áreas em detrimento de um trabalho mais aprofundado sobre os conteúdos que serão desenvolvidos no ensino fundamental e médio. [...] é preciso identificar, entre outros aspectos, obstáculos epistemológicos, obstáculos didáticos, relação desses conteúdos com o mundo real, sua aplicação em outras disciplinas, sua inserção histórica. Esses dois

4 MATTHEWS, Michael R. História, Filosofia e ensino de ciências: a tendência atual de reaproximação. Caderno Catarinense de Ensino de Física, vol. 12, n.3, p.164-214, 1995.

5 ZANETIC, João. Física também é cultura. Tese (Doutorado). Faculdade de Educação, Universidade de São Paulo, 1989 .

${ }^{6}$ MOURA, B. A. Formação crítico-transformadora de professores de Física: uma proposta a partir da História da Ciência. 2012. 309 f. Tese (doutorado). Faculdade de Educação, Instituto de Física, Instituto de Química, Instituto de Biociências. Universidade de São Paulo, São Paulo, 2012, p.79-82. 


\section{Khronos, Revista de História da Ciência \\ ISSN 2447-2158 - no 4, agosto 2017}

níveis de apropriação do conteúdo devem estar presentes na formação do professor. ${ }^{7}$

O referido parecer do Conselho Nacional de Educação (CNE/CP no 9/2001) aponta ainda problemas considerados históricos nos cursos de licenciatura, como a necessidade de "definição de currículos próprios da Licenciatura que não se confundam com o Bacharelado ou com a antiga formação de professores que ficou caracterizada como modelo ' $3+1$ ”' (p. 6). Neste modelo tradicional de formação de professores a ênfase está contida na formação nos conteúdos de área e “a atuação destes como 'licenciados' torna-se residual e é vista, dentro dos muros da universidade, como 'inferior', em meio à complexidade dos conteúdos da 'área”' (p. 16).

Na Universidade de São Paulo, o modelo 3+1 para formação dos professores vigorou por bastante tempo, desde a incorporação do Instituto Educacional de São Paulo, quando a formação de professores migrou para dentro da universidade e acrescentou-se um ano ao curso de bacharelado para quem desejasse uma formação para atuar como professor. Especificamente no Instituto de Física, esse foi o modelo para formação de físicos-educadores que vigorou até 1993, quando ocorreu a separação dos cursos de Licenciatura e Bacharelado em Física, que passaram a ter ingressos distintos no vestibular e, dessa forma, também currículos diferenciados.

A mudança no currículo da Licenciatura em Física incluiu a reformulação das disciplinas existentes e a criação de novas disciplinas que tratassem de conteúdos de física básica presentes no nível médio. Em uma entrevista, concedida em 1998, Zanetic ${ }^{8}$ explica:

O currículo dessa nova licenciatura visava oferecer, entre outras novidades, disciplinas especializadas em alguns conteúdos tradicionalmente presentes nas físicas básicas, mas que muitas vezes não são abordados de maneira adequada. Ao mesmo tempo, foram introduzidas disciplinas que deveriam oferecer diferentes enfoques metodológicos. Isso ocorreu, por exemplo, com os temas relacionados à termodinâmica, óptica e gravitação?.

Nesse artigo discutimos a história da disciplina Gravitação, desde sua implementação em 1993 até o presente ano de 2017. Acreditamos que essa história é especialmente interessante em razão dessa disciplina ser obrigatória na grade curricular e propor o ensino de conteúdos de Física, no que se referem às teorias da gravidade, através do desenvolvimento histórico dos episódios e de discussões filosóficas inerentes a estes conceitos. Assim ela leva para a formação de professores de Física a proposta de ensinar conceitos físicos numa perspectiva diferenciada das demais disciplinas introdutórias de Física.

Buscamos apresentar os pressupostos teóricos que embasaram a escolha dos episódios a serem discutidos durante a disciplina, bem como a elaboração do material de apoio desenvolvido

$7 \mathrm{CNE} / \mathrm{CP} \mathrm{n}^{\circ}$ 9/2001. Parecer do Conselho Nacional de Educação. Disponível em http://portal.mec.gov.br/cne/arquivos/pdf/009.pdf

8 SILVA, J. C. Um exemplo do uso da bistória e filosofia de física: disciplina FEP 156 - Gravitação. Dissertação (Mestrado em Ensino de Física). Faculdade de Educação, Instituto de Física, Universidade de São Paulo, 1998.

9 SILVA, J. C., 1998. Op. Cit. p.28-29. 
para os estudantes. Em seguida, discutimos alguns condicionantes para implementação e sustentação da proposta ao longo dos anos.

\section{A disciplina Gravitação no curso de Licenciatura em Física da USP}

A elaboração de um novo currículo para o curso de Licenciatura em Física culminou na reestruturação de disciplinas de Física Básica, como Mecânica e Fundamentos de Mecânica, e na inserção de novas disciplinas, tais como Óptica, Termodinâmica e Gravitação. Estas disciplinas foram introduzidas no currículo para tentar apresentar a física como um empreendimento humano, como parte de um processo histórico que influencia e é influenciado pelas visões de mundo dos sujeitos que dele participa. Dessa forma, algumas disciplinas de Física do curso de Licenciatura se diferenciaram claramente da estrutura e dos conteúdos daquelas do Bacharelado.

A Gravitação entrou no novo currículo da Licenciatura como uma tentativa de inserir uma disciplina de Física com abordagem histórica, mostrando a física como um empreendimento histórico e social ${ }^{10}$. Ela foi estruturada desde sua proposta inicial para apresentar os conceitos da Gravitação através dos episódios da história da ciência, tendo como eixo epistemológico as ideias apresentadas por Thomas Kuhn. A proposta foi assim inspirada, principalmente, nas obras $A$ estrutura das revoluções cientificas e A Revolução Copernicana ${ }^{11}$.

Foi elaborado um material de apoio para a disciplina (Notas de Aula de Gravitação) no qual os episódios selecionados e a apresentação dos mesmos seguem os estágios do Pré-Paradigma, Ciência Normal, Crise e Paradigma. Estágios estes que Kuhn delineia no livro A estrutura das Revolucões Científicas. De acordo com as palavras do elaborador da proposta,

Como o conteúdo de Gravitação, visto na perspectiva histórica, inclui várias revoluções científicas com superação de paradigmas, nada mais natural para mim que utilizar a obra de Kuhn. Minha intenção, como já esclareci em respostas anteriores, era fundir a história e a filosofia da ciência numa única experiência didática [...]. De qualquer forma, através da tríade ciência normal-crise-revolução científica, a abordagem kuhniana também permite esse tipo de procedimento em sala de aula. Notamos assim mais uma utilidade para a aproximação entre filosofia e história em sala de aula ${ }^{12}$.

É importante destacar que a disciplina Gravitação foi proposta para o primeiro ano da formação dos futuros professores de Física, momento em que os estudantes ainda se encontram em período de adaptação ao ritmo da vida universitária e à descoberta de novos conhecimentos físicos. Isso marcou as características desta disciplina, que visou justamente propiciar ao estudante recém ingressante no curso de Licenciatura em Física um novo olhar para esta ciência, que compreendesse o conhecimento físico como um produto histórico e social da humanidade.

10 SILVA, J. C. Um exemplo do uso da história e filosofia de física: disciplina FEP 156 - Gravitação. Dissertação (Mestrado em Ensino de Física). Faculdade de Educação, Instituto de Física, Universidade de São Paulo, 1998, p. 29.

11 KUHN, Thomas. A revolução copernicana. Lisboa: Edições 70, 1990. A estrutura das revolucões científicas. São Paulo: Perspectiva, 1994.

12 ZANETIC, 1998 apud SILVA, 1998 p.34. Ver nota 8. 
Dessa maneira, esta disciplina foi proposta e encomendada, desde sua concepção, para oferecer aos estudantes do $1^{\circ}$ ano da Licenciatura uma visão humanística de uma temática específica do conhecimento físico, a evolução dos modelos de gravidade, buscando trazer discussões conceituais e expressões matemáticas junto à história e à filosofia da ciência.

Ao tratar da história da gravitação como uma especificidade do conhecimento científico alguns aspectos controversos da natureza da ciência podem ter mais potencialidade de serem discutidos junto a esses episódios. Por exemplo, a gravitação universal ter se desenvolvido intimamente com a atividade de observação do céu pode permitir problematizar facilmente o papel da observação do céu na construção destas teorias ao longo da história da humanidade.

\section{Episódios da história da Gravitação sob o olhar de Thomas Kuhn}

Por que os corpos "caem"? Por que vemos os astros no cén girar ao redor da Terra? Há algo que atrai tudo para o centro da Terra? A Terra se move ou está parada? Qual é o centro do universo? Para onde vai a matéria no Universo? Essas e outras perguntas fundamentais inquietaram a humanidade desde o século IV AC, por meio dos filósofos gregos, e mais acentuadamente ao longo dos últimos séculos, e permearam as discussões que levaram à elaboração das distintas teorias da Gravitação propostas ao longo da história da humanidade.

Uma das estórias mais difundidas junto aos conceitos da Gravitação Universal é o episódio da queda da maçã. Em algumas versões, associa-se a queda da maçã como o evento que teria possibilitado Newton chegar às ideias acerca da gravidade. Entretanto, existem várias versões desta história e desta forma torna-se importante que professores de Física tenham conhecimento das versões mitificadas que enaltece este acontecimento e reduzem os passos e caminhos tortuosos que Newton percorreu até a culminação da Gravitação Universal. Nas sessões seguintes apresentaremos um olhar de historiadores da ciência acerca desta história.

Diversos historiadores e filósofos da ciência investigaram e propuseram interpretações epistemológicas acerca dos pressupostos das mudanças científicas que envolveram as teorias da Gravitação. Os eventos associados à transição dos modelos de Sistema Solar, por exemplo, ficaram amplamente conhecidos na literatura como a "Revolução Copernicana", e envolveram discussões sobre a necessidade de uma explicação física e dinâmica para os movimentos do Sistema Solar. Essa transição e a consequente aceitação do modelo heliocêntrico pela comunidade científica teve um papel de destaque na história da Gravitação.

Um dos estudiosos da chamada "Revolução Copernicana" foi o físico, historiador e filósofo da ciência estadunidense Thomas Kuhn. Em sua proposta, os critérios de escolha e aceitabilidade das teorias científicas baseadas apenas nos procedimentos internos da ciência foram densamente questionados, e o estudo de como as teorias cientificas se desenvolveram, ou seja, o olhar histórico passou à ser considerado na compreensão da dinâmica das teorias científicas.

Fatores antes considerados "valores não cognitivos" passaram a ser considerados na escolha de teorias por parte de cientistas ou de uma comunidade de cientistas. A epistemologia de Kuhn, por exemplo, trouxe à tona a possibilidade de critérios subjetivos à pratica científica e até mesmo sociais serem determinantes no sucesso ou na aceitabilidade das teorias cientificas, se opondo a análise racional dos processo de construção da ciência. 
Uma das críticas mais importantes ao convencionalismo é apresentada por Thomas $\mathrm{Kuhn}^{13}$, em um importantes livro que trata da transição do modelo heliocêntrico para o geocêntrico, A Revolução Copernicana: astronomia planetária no desenvolvimento do pensamento ocidental, de 1957. A partir de estudos de fontes originais, Kuhn apresenta diversos elementos que evidenciam que o sistema copernicano era pelo menos tão complexo quanto o ptolomaico. Isso pode ser evidenciado, por exemplo, pelo fato de que o modelo de Copérnico usa tantos epiciclos quanto o de Ptolomeu ${ }^{14}$.

Um dos primeiros paradigmas da Gravitação pode ser interpretado como o paradigma da visão de mundo física de Aristóteles, proposto em meados do século IV AC. A física aristotélica se apresentava como um conjunto de valores, conceitos, técnicas partilhadas e amplamente aceitas pelos estudiosos da fenomenologia natural. Sua aceitação perdurou cerca de vinte séculos, até e segunda metade do século XVII, quando um novo paradigma entra em cena e ganha a disputa - o paradigma da Gravitação Newtoniana.

O modelo físico gravitacional proposto por Aristóteles era coerente com a observação dos fenômenos tanto terrestres quanto celestes. Os objetos terrestres ou celestes apresentam a tendência em se deslocar para o centro do universo e este coincidia com o centro da Terra.

A ideia física dos movimentos naturais e violentos se mostrava uma base coerente e sólida para explicar os fenômenos terrestres quanto celestes. O paradigma aristotélico também oferecia boas explicações para os fenômenos observáveis, tais como as estações do ano e as fases da Lua; a previsão de eclipses lunares e solares; a queda dos graves na superfície da Terra; o movimento dos corpos celestes ao redor da Terra.

O estágio da ciência normal representa para Kuhn a tentativa de encaixar os fenômenos naturais nas explicações fornecidas pelo paradigma. Kuhn utiliza a metáfora do quebra-cabeça para esclarecer os significados dos trabalhos da ciência normal. O quebra-cabeça seria constituído pelos problemas escolhidos e admitidos pela comunidade cientifica, os quais são os únicos passiveis de serem resolvidos pela comunidade. Assim o paradigma também define os problemas a serem resolvidos, o que torna a ciência normal uma prática conservadora e circular.

A ciência normal se constrói de maneira que o paradigma raramente é questionado, se torna um dogma, que se configura em um aspecto rígido e necessário para o progresso científico. Seria assim o período de não questionamento do paradigma uma característica que permite e sustenta o progresso científico.

A força do paradigma aristotélico da Gravitação era evidenciada pelo uso desse modelo pela ciência normal na elaboração dos modelos astronômicos de Sistema Solar até o século XVI. O modelo geocêntrico proposto por Claudius Ptolomeu no século II representa um exemplo de modelo produzido pela prática da ciência normal, em que a sustentação principal se dá pelos pressupostos do paradigma da imobilidade da Terra, localizada no centro dos movimentos de todos os corpos no universo.

O período de crise paradigmática representa para Kuhn o momento em que novos fenômenos ou observações e perguntas surgem e não são respondidos satisfatoriamente pelo paradigma dominante. Para Kuhn, as hipóteses e as técnicas da astronomia antiga, no século XVI, se

\footnotetext{
13 Ver nota 11.

${ }^{14}$ COPÉRNICO, Nicolau. Commentariolus - Pequeno comentário de Nicolau Copérnico sobre suas próprias hipóteses acerca dos movimentos celestes. Tradução e notas: Roberto A. Martins. São Paulo, Nova Stella, 1990.
} 
encontravam em um período de crise com outros modelos alternativos para o Sistema Solar aparecido na sociedade ocidental ${ }^{15}$.

Alguns problemas astronômicos não eram explicados de maneira convincente pelo paradigma geocêntrico de Ptolomeu, tais como: 1. O movimento retrógrado dos planetas; 2. Porque Vênus e Mercúrio sempre são vistos nas proximidades do Sol; 3. Porque Marte, Júpiter e Saturno podiam ser vistos em oposição ao Sol; 4. Qual a ordem de afastamento dos planetas. Esses problemas agudizam a crise paradigmática.

Essa situação gera para Kuhn a fase pré-paradigmática, quando novos modelos concorrem entre si visando substituir o paradigma vigente. Assim nessa fase pré-paradigmática, vão ser propostos candidatos a paradigma como o modelo de Tycho Brahe (1546 -1601) que propõe um modelo "alternativo" para o Sistema Solar, com a Terra no centro do movimento do Sol e os demais planetas girando ao redor do Sol, e não da Terra, e o modelo heliocêntrico proposto por Nicolau Copérnico (1473 - 1543), no século XVI, inspirado no modelo heliocêntrico de Aristarco de Samos do século III AC.

Essa fase pré-paradigmática vai caminhar para sua conclusão com a opção de comunidade ciente pela proposta de Copérnico que vai ser articulada por muitos cientistas como Kepler, Galileu e Newton, entre outros. Isso vai provocar uma situação de revolução um novo paradigma é escolhido pela comunidade científica, que passa assim a praticá-lo e aprimorá-lo nas ações da ciência normal.

Em razão dos conceitos que a Gravitação aborda tratarem de conceitos relacionados à astronomia, que por sua vez envolvem a prática da observação do céu, essa especificidade deve ser levada em conta ao apresentar o desenvolvimento e construção das teorias astronômicas. Por exemplo, a gravitação universal ter se desenvolvido intimamente com a atividade de observação do céu pode permitir problematizar facilmente o papel da observação do céu na construção destas teorias ao longo da história da humanidade. Desta maneira, caberia questionarmos qual carga teórica está se relacionando com a observação e como elas participam da construção de uma teoria astronômica.

A ciência como um conhecimento objetivo desenvolvido por meio da indução a partir de experimentos que descrevem a realidade, vem sendo criticada até os dias de hoje por filósofos, historiadores e sociólogos da ciência. Afirmações como "os experimentos mostram resultados isentos de interpretações teóricas prévias" ou "toda observação nos fornece informações isentas de interpretações", que podem ser associadas ao positivismo lógico ou à tradição empirista, receberam inúmeras críticas de filósofos ou historiadores da ciência tais como Norwood R. Hanson (1924-1967), Thomas S. Kuhn (1922 - 1996), Paul K. Feyerabend (1924 - 1994) e Imre Lakatos (1922 - 1974).

A idealização das entidades observadas é uma das tarefas árduas que cabe à ciência lidar. Entretanto, nenhuma entidade observada é um caso direto e ingênuo da natureza. O processo de interpretação dos objetos observados envolve também outros elementos inerentes à ciência, tais como representá-los ou manipulá-los matematicamente. Isso vai além da mera representação dos elementos do mundo observável, fazendo parte da imaginação e da ficção na construção desses conhecimentos ${ }^{16}$.

15 KUHN, Thomas. A revolução copernicana. Lisboa: Edições 70, 1990.

16 MATTHEWS, Michael R. História, Filosofia e ensino de ciências: a tendência atual de reaproximação. Caderno Catarinense de Ensino de Física, vol. 12, n.3, p.183, 1995. 


\section{A construção de um material paradidático: as Notas de aula de Gravitação}

Em muitos materiais e manuais didáticos o termo "gravitação" está associado à Gravitação Universal e ao personagem Isaac Newton. No entanto, muitos outros pensadores estiveram presentes na história das teorias da gravitação, tais como personagens mais famosos, como Kepler, Newton e Einstein, até outros personagens que quando mencionados são brevemente introduzidos como Copérnico, Descartes e Galileu ou então aqueles raramente abordados, como Aristóteles, Aristarco, Pitágoras, Rethicus, Thomas Harriot, Leibniz, Eddington, dentre outros.

Os manuais didáticos, por sua vez, desempenham grande papel para a seleção e abordagem dos conteúdos que o professor irá fazer em sala de aula. Muitas vezes ele é ancora para o professor preparar suas aulas e propor atividades e exemplos que explorem determinados conceitos.

Sabemos por diversas pesquisas que os livros apresentam uma história distorcida, anacrônica, que enfatiza os mitos e ainda privilegia apenas os personagens mais famosos de determinado episódio, mostrando ainda a história dos vencedores.

Grande parte dos livros didáticos de física adotados pelo Programa Nacional do Livro didático do Ensino Médio (PNLEM), por sua vez, apresenta o tema gravitação com grande destaque, em muitos deles como um capítulo do livro a ser abordado junto aos conteúdos de mecânica (SIMÕES, 2008) ${ }^{17}$.

No entanto, embora em alguns livros haja menção ao conteúdo histórico e filosófico, muitos ainda apresentam a teoria da gravitação como um resumo da aplicação das Leis de Kepler e da Lei da Gravitação Universal aplicadas aos planetas do Sistema Solar. Isso reflete um ensino que enfatiza os aspectos matemáticos e memorizáveis da física, em detrimento dos ricos aspectos culturais, históricos e filosóficos do conhecimento físico (ZANETIC, 1989) ${ }^{18}$.

Contudo, ainda vemos que a maioria dos livros apresenta o desenvolvimento da gravitação universal sem apresentar suas limitações, alguns dos debates e erros, e se limitam a uma história linear, como se os acontecimentos anteriores sucedem e são substituídos de maneira simples e direta pelos eventos recentes.

Ainda ao se narrar uma história, sabemos que há diversas maneiras de explorá-la. Na história da ciência não seria diferente: historiadores de distintas nacionalidades ou imersos em diferentes culturas narram acontecimentos muito semelhantes com distintas ênfases e olhares, e assim acabam por fornecer distintas interpretações sobre a história narrada. O fato de existir distintas interpretações da história dos conhecimentos científicos torna por si só a história da ciência um belíssimo e fascinante olhar.

A partir da discussão da história dos personagens e dos acontecimentos que envolveram a construção desses conceitos realizada por historiadores da ciência, principalmente da década de 1970, foram elaboradas notas de aula que pudessem ser utilizadas ao longo da disciplina. Tais

17 SIMÕES, C. C. Elementos de astronomia nos livros didáticos de Física. Dissertação (Mestrado em Ensino de Ciências e Matemática) Pontifícia Universidade Católica de Minas Gerais, Belo Horizonte, Minas Gerais, 2008.

18 Ver nota 5. 
notas de aula ${ }^{19}$ se encontravam disponíveis a qualquer professor do IFUSP que optasse por utilizá-la em suas aulas. As notas de aula se constituem em um texto escrito, na forma de narrativa, e estruturada nos seguintes capítulos:

1. Da roda aos céus

2. O sistema de mundo aristotélico-ptolomaico

3. O tamanho do mundo Grego

4. Algumas ideias solte a mecânica na Idade Média

5. A Revolução copernicana

6. Repercussões dessa ciência na literatura universal

7. Do círculo perfeito à elipse

8. Algumas contribuições de Galilcu Galilei

9. Galileu e Kepler: aspectos pedagógicos e literários

10. Os "Principia" de Isaac Newton

11. Triunfos da mecânica newtoniana depois de Newton

12. Mais alguns tópicos gravitacionais.

Para a disciplina em foco que está sendo apresentada neste artigo, o autor e professor desta disciplina por quase duas décadas optou por iniciar as discussões a partir das primeiras noções gregas sobre a queda dos corpos e os movimentos dos objetos celestes. Dessa forma, nos capítulos 1 a 3 foram introduzidas algumas contribuições dos gregos Platão, Pitágoras, Arquimedes, Aristóteles e Aristarco de Samos, destacando como eles contribuíram para a articulação do paradigma da física de Aristóteles, dos movimentos naturais e violentos.

Em seguida, no capítulo 4, são introduzidos alguns personagens que teriam contribuído com a Física no período medieval, tais como Filopono, Buridan, e Oresme, contribuintes para noções de física como a ideia do impetus e da resistência do ar. Estes personagens aparecem com algumas teorias candidatas a paradigma, em oposição ao paradigma aristotélico.

Copérnico e a proposta do heliocentrismo como um novo candidato a paradigma do modelo de Sistema Solar, se opondo ao paradigma do modelo geocêntrico e da Terra no centro do universo, aparece no capítulo 5 deste material.

Em seguida, Kepler e Galileu são apresentados como grandes gigantes que contribuíram para os trabalhos de Newton para a Gravitação Universal. Por fim, é introduzida brevemente a Teoria da Relatividade Geral, por Einstein, como uma proposta alternativa e moderna à Gravitação Universal. As notas de aula ainda apresentam algumas repercussões dessa física na literatura.

19 ZANETIC, João. Notas de aula de Gravitação (Texto não publicado). Instituto de Física, Universidade de São Paulo, versão 2007. 


\section{A implementação da proposta, o panorama atual e as perspectivas futuras}

O curso de Licenciatura em Física tem entrada anual de alunos em uma turma no diurno (50 alunos) e outra no noturno (60 alunos). A disciplina Gravitação tem lugar na grade curricular no segundo semestre do primeiro ano do curso de Licenciatura em Física ${ }^{20}$ para ambas as turmas.

No período de 1993 até 2011 (ano em que o docente se aposentou) o professor João Zanetic ministrou essa disciplina para os alunos da Licenciatura em Física. De 2012 a 2014 a disciplina foi ministrada pelo professor Ivã Gurgel e de 2015 a 2016 pela professora Doutora Valéria S. Dias, que a ministrará também nesse ano de 201721. Em quase todos os anos, as Notas de Aula de Gravitação foram utilizadas na disciplina e esta manteve o viés metodológico histórico-filosófico.

Os três professores citados nominalmente (Zanetic, Gurgel e Dias) foram aqueles que mais ministraram a disciplina, sendo destacadamente o criador da disciplina aquele quem mais a ministrou até o momento. Esse é um dado importante para analisarmos a sustentação da proposta inicial da disciplina ao longo do tempo, visto que quando olhamos para as linhas de pesquisa e a produção acadêmica dos três professores é evidente o interesse desses docentes pela inserção e valorização da história e da filosofia da ciência no ensino de ciências e na formação de professores.

Essa característica comum a esses docentes parece apontar para uma condição necessária para manutenção do espírito formativo inicialmente proposto para a disciplina. O que não significa, necessariamente, que a disciplina tem sido ministrada da mesma forma por tais professores. Aliás, um mesmo professor realiza ajustes e aperfeiçoamentos a cada oferecimento.

Nos anos seguintes, 94 e 95, procurei melhorar os textos, dando uma coesão maior do que na primeira tentativa, formando um conjunto de textos que, vindo desde a antiguidade, chegasse não apenas a Newton, mas também esboçasse algo da última teoria da gravitação que provoca também uma revolução científica, que era decorrente da relatividade de Einstein ${ }^{22}$.

Também ao olharmos as Notas de Aula ${ }^{23}$ vemos esse movimento, por exemplo, nas versões utilizadas até o início da década de 2000, as contribuições do trabalho do historiador Roberto de Andrade Martins não haviam sido incorporadas no texto.

Outras mudanças significativas ocorreram ao longo dos anos e talvez a mais importante seja o empobrecimento da exploração das relações entre a produção do conhecimento físico e a literatura, desde 2012. Uma perda, claramente associada a não presença do professor Zanetic, que também pode significar fortalecimento (ou ênfase) em outros aspectos da proposta.

${ }^{20}$ Essa disciplina também é obrigatória no currículo do curso de Licenciatura em Matemática do Instituto de Matemática e Estatística da USP (IME), porém, a oferta no IME não será discutida nesse artigo.

${ }^{21}$ Nos semestres em que a disciplina não foi ministrada pelos professores nominados, outros docentes do IF ou alunos de pós-graduação o fizeram. Apenas um deles não distribuiu as Notas de Aula para os alunos e, nessa ocasião, a disciplina teve uma forte ênfase operacional matemática.

22 SILVA, J. C. Um exemplo do uso da história e filosofia de física: disciplina FEP 156 - Gravitacão. Dissertação (Mestrado em Ensino de Física). Faculdade de Educação, Instituto de Física, Universidade de São Paulo, 1998 , p. 38.

${ }^{23}$ ZANETIC, João. Notas de aula de Gravitação (Texto não publicado). Instituto de Física, Universidade de São Paulo, versão 2007. 
Nos últimos anos, sob responsabilidade da professora Dias, a disciplina talvez esteja perdendo a forte orientação epistemológica kuhniana. Mesmo que se mantenha a perspectiva de interpretação kuhniana e a leitura dos paradigmas, de estabelecimento da ciência normal e da revolução científica permaneça nas aulas, é possível perceber a paulatina introdução de outras possibilidades de interpretação. Isso se deve, sobretudo, pela presença de uma pesquisadora que, em parceria com a docente, busca adicionar à formação dos estudantes a clareza que não existe uma única forma de interpretar um episódio histórico e que toda leitura é, necessariamente, influenciada pelos valores, pelas crenças, pela cultura daquele que a faz.

\section{Considerações Finais}

Este perfil de disciplina é raro nos currículos das licenciaturas em Física do Brasil, sendo a Gravitaģão um caso específico oferecido no curso de Licenciatura em Física do Instituto de Física da USP. Trata-se de uma disciplina obrigatória para os estudantes regulares do $2^{\circ}$ semestre de curso, e contempla a proposta de introduzir conteúdos de Física através de uma nova maneira de pensar o processo de construção das teorias da Gravitação ao longo da história, trazendo uma interpretação da evolução desses conceitos segundo a epistemologia de Thomas Kuhn.

A proposta desta disciplina pode ser considerada como um tipo de disciplina integradora, ou seja, que une a perspectiva histórica e filosófica da ciência com o ensino de conteúdos e conceitos de Física, em que uma das abordagens (a abordagem histórica e filosófica) age como linha condutora de todas as discussões que envolvem o conteúdo específico em questão.

Os estudantes, por sua vez, pelo fato de estarem no primeiro ano da graduação, apresentam tanto reações negativas quanto positivas a esta proposta. Um dos fatores que influenciaram sua visão acerca dessa disciplina, se deve em razão de que muitos deles nunca vivenciaram uma discussão histórica e filosófica de conceitos físicos. A Física que muitos conheciam até este momento se pautava apenas na resolução de problemas algébricos que exigem muito mais a aplicação de fórmulas do que a análise conceitual.

Dessa forma, a disciplina Gravitação pode contribuir para ultrapassar as fronteiras do conhecimento físico que é apresentado aos estudantes no início de suas carreiras docente, possibilitando uma reflexão que vai além da resolução de problemas algébricos e das discussões das fórmulas prontas e acabadas. Ao apresentar o processo de construção de teorias científicas, tal disciplina contribui para uma formação mais profunda dos próprios conteúdos científicos.

Ao perceber que o cerne da proposta se manteve inalterado por mais de duas décadas, isso mostra o quanto a proposta é viável em cursos de formação de professores de Física. A breve análise dos condicionantes para a manutenção da proposta revela que o perfil (a formação e o interesse) dos professores que a ministram pode contribuir para a manutenção da proposta, bem como também a escolha do material didático de apoio. No caso de Gravitação, há uma vantagem no uso de um material paradidático que surgiu especialmente para atender aos objetivos pedagógicos que a disciplina demanda, e este se apresenta como elemento essencial para sustentação dos pressupostos epistemológicos e metodológicos que tem caracterizado as atividades da disciplina. 